\title{
RANCANG BANGUN DATA MART DAN PURWARUPA DASHBOARD UNTUK VISUALISASI PERFORMA AKADEMIK
}

\author{
Kurniawan Jatmika, Adhistya Erna P., Ari Cahyono \\ Jurusan Teknik Elektro dan Teknologi Informasi, Fakultas Teknik, \\ Universitas Gadjah Mada Yogyakarta, \\ Jln. Grafika 2, Yogyakarta, 55281 \\ Telp: (0274) 547506, Fax: (0274) 510983 \\ E-mail: kurniawan.jatmika@mail.mti.ugm.ac.id
}

\begin{abstract}
University often had enormous amount of data stored but meet difficulties in organizing and constructing information. These conditions also generally happened in STIKOM Surabaya, especially in S1 Sistem Informasi study program, whereas the head of S1 Sistem Informasi study program meet difficulties in reviewing the performance of the study program. Based on that, a system able to facilitate the information gathering and presentation is needed. For this requirement, a data storage with data mart schema can be used which then directly connected to a dashboard system to facilitate the monitoring process of study program's performance. After the system had been designed and implemented, it can be concluded that: star schema design supporting and facilitating the design and implementation process of the academic data mart and the dashboard system, the system able to help the head of study program in evaluating the study program's academic performance, and the user accepting the system well.
\end{abstract}

\begin{abstract}
Abstrak
Perguruan tinggi seringkali mempunyai simpanan data yang banyak namun kesulitan dalam memilah dan menyusun informasi. Kondisi ini secara umum juga terjadi di STIKOM Surabaya, khususnya di Program Studi S1 Sistem Informasi, dimana Kepala Program Studi S1 Sistem Informasi kesulitan dalam meninjau performa program studi yang dipimpinnya. Berdasarkan permasalahan tersebut maka dibutuhkan sebuah sistem yang mampu memfasilitasi proses pengumpulan dan penyajian informasi. Untuk keperluan ini dapat digunakan simpanan data dengan skema data mart yang terhubung secara langsung ke dalam sebuah dashboard system untuk mempermudah proses monitoring performa program studi. Setelah sistem selesai dirancang dan dibangun, dapat disimpulkan bahwa: desain star schema mendukung dan memudahkan proses rancang bangun data mart akademik dan dashboard system, sistem mampu membantu Kepala Program Studi S1 Sistem Informasi dalam mengevaluasi performa akademik program studi, dan pengguna menerima dengan baik sistem yang sudah dirancang
\end{abstract} bangun.

Kata kunci: data mart, dashboard system, performa akademik, perguruan tinggi.

\section{PENDAHULUAN}

Penelitian mengenai sistem pendukung keputusan untuk kebutuhan manajemen di perguruan tinggi di negara Eropa sudah dilaksanakan oleh Stanciu dkk. (2009) dan Paunica dkk. (2010). Penelitian Stanciu dkk. (2009) menekankan pada kriteria pemilihan lingkungan pengembangan dalam merancang sistem pendukung manajemen universitas. Kesimpulan dari penelitian ini adalah bahwa teknologi data warehouse adalah solusi yang efisien untuk analisis data dan dapat menyediakan dukungan yang diperlukan untuk mendukung keputusan dalam manajemen perguruan tinggi. Kemudian penelitian Paunica dkk. (2010) secara spesifik mengukur performa dari institusi pendidikan menggunakan data warehouse. Sistem software yang dihasilkan dalam penelitian ini menawarkan kemungkinan adanya analisis untuk hasil dari proses pendidikan meliputi performa pendidikan dan efisiensi biaya.

Lebih lanjut, penelitian tentang rancang bangun data warehouse terhadap data akademik di perguruan tinggi di Indonesia juga sudah dilaksanakan oleh Prasetija (2010) dan Prasetyo (2011). Pada penelitian Prasetija (2010) dibangun sebuah purwarupa data warehouse pada sistem informasi manajemen perguruan tinggi dengan studi kasus STIKOM Surabaya yang mengacu kepada salah satu sub dari standar 
11 akreditasi perguruan tinggi yaitu lulusan. Dengan studi kasus dan fokus pembahasan yang berbeda Prasetyo (2011) juga telah melakukan perancangan data warehouse sistem informasi eksekutif dengan studi kasus data akademik Program Studi Teknik Elektro Fakultas Teknik Universitas Gadjah Mada. Keempat penelitian tersebut, yaitu Stanciu (2009), Paunica (2010), Prasetija (2010), dan Prasetyo (2011), menggunakan star schema dalam proses pengembangan data warehouse. Jadi dapat disimpulkan bahwa star schema diterima dan digunakan secara umum dalam pengembangan data warehouse di dunia pendidikan.

Penelitian tentang sistem pendukung keputusan yang menggunakan analisis statistik kemudian dilaksanakan oleh Ghaseminejad \& Brantingham (2010). Penelitian ini dilaksanakan untuk mensistemkan analisis statistik terhadap laporan kejahatan dan penanganannya di Kanada. Penelitian tersebut menggunakan alat bantu Microsoft Excel dalam melakukan pengolahan dan pemodelan data. Berdasarkan penelitianpenelitian yang sudah dikaji, maka penelitian ini difokuskan kepada:

1. Proses identifikasi terhadap purwarupa data warehouse Stanciu dkk. (2009), Paunica dkk. (2010), Prasetija (2010) dan Prasetyo (2011) untuk dijadikan landasan rancang bangun data mart Prodi S1 Sistem Informasi STIKOM Surabaya. Dikatakan data mart karena merupakan pengembangan data warehouse secara departemental, karena hanya berfokus pada variabel akademik yang ada pada Prodi S1 Sistem Informasi. Data mart yang telah dibangun kemudian diolah lebih lanjut untuk dikembangkan sebagai penyedia data bagi sistem pendukung keputusan peningkatan kualitas akademik Prodi S1 Sistem Informasi.

2. Proses implementasi dashboard system dengan studi kasus data akademik mengacu pada analisis statistik regresi yang diterapkan Ghaseminejad \& Brantingham (2010) pada data kejahatan. Implementasi dashboard system ini juga mengacu kepada penelitian Paunica (2010) mengenai analisis dari proses pendidikan. Kedua penelitian ini mengalami keterbatasan pada penyajian keluarannya yang sulit dicerna pengguna non teknis.

\section{METODOLOGI}

Metodologi pengerjaan penelitian ini dimulai dari data warehouse, data mart, dashboard system. Untuk dashboard system akan dilihat indikator-indikator penting pada dashboard yang akan dibangun serta kesalahan yang sering dilakukan saat pembangunan dashboard.

\subsection{Data Warehouse}

Marakas (2003) mendefinisikan data warehouse sebagai salinan dari data transaksi yang secara spesifik distruktur untuk melakukan pembacaan data, analisis dan pelaporan. Data yang ada di dalam data warehouse merupakan data salinan dari transaksi yang tidak diperbarui atau diubah kemudian oleh sistem transaksi. Perlu dicatat juga bahwa data yang ada dalam data warehouse distruktur sedemikian rupa dan mungkin ditransformasikan ketika ditempatkan ke dalam data warehouse.

Data warehouse mempunyai beberapa fungsi utama, yaitu :

1. Sebagai gambaran langsung dari aturan bisnis dari perusahaan.

2. Sebagai titik penyimpanan informasi strategis.

3. Sebagai penyimpanan historis dari informasi strategis.

4. Sebagai sumber dari informasi yang kemudian diberikan kepada data mart.

5. Sebagai sumber dari data yang stabil, tidak tergantung kepada perubahan dari proses bisnis.

Data warehouse merupakan tempat penyimpanan data perusahaan atau institusi yang disusun sedemikian rupa sehingga mengandung makna dan untuk analisis dan pelaporan. Sehingga sebuah data warehouse merupakan sumber informasi yang datanya diperoleh dari Online Transaction Processing (OLTP). Biasanya data warehouse ini menyimpan data yang bersifat historis. Seperti yang dikatakan oleh Turban dkk (2006), data warehouse adalah sebuah basis data komprehensif yang mendukung semua analisis keputusan yang diperlukan oleh suatu organisasi dengan menyediakan ringkasan dan rincian informasi. Sedangkan menurut Connolly dan Begg (2001) seperti juga didefinisikan oleh Inmon pada Ponniah (2010), data warehouse adalah suatu kumpulan data yang bersifat subject-oriented, integrated, timevariant, dan non-volatile dalam mendukung proses pengambilan keputusan.

Dari Gambar 1, terlihat aliran data dari basis data operasional ke data warehouse, dilanjutkan dengan pengembangan aplikasi (reporting) yang akan digunakan untuk menganalisis dan mengevaluasi bisnis. Seperti apa yang disampaikan oleh Inmon (2005), data mengalir dari lingkungan operasional ke dalam data warehouse dimana data mengalami transformasi dari tingkatan operasional ke tingkatan data warehouse. 


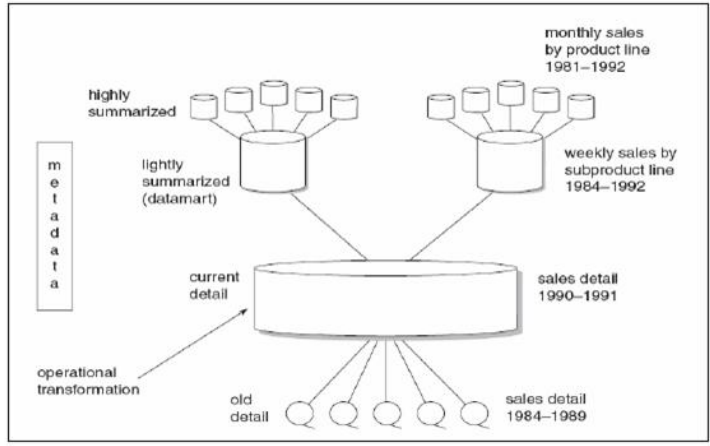

Gambar 1. Aliran data dari basis data operasional menuju data warehouse (Inmon, 2005)

Masih menurut Inmon (2005) Pada perumusan data yang dapat dilihat pada Gambar 2, data disampaikan dari current detail data ke order detail. Setelah data diringkas, data tersebut disampaikan dari current detail ke lighty summarized data, kemudian dari lightly summarized data ke highly summarized data. Setiap perusahaan dalam mencapai tujuannya menggunakan strategi yang berbeda, hal ini membuat jenis dan tipe data bahkan arsitektur dan proses bisnisnya ikut berbeda. Sehingga dalam melakukan perancangan data warehouse harus ditentukan arsitektur yang cocok untuk pengembangan data warehouse. Dari gambar 2, terlihat proses pengolahan data operasional sebelum dimasukkan ke dalam data warehouse melalui staging area terlebih dahulu. Staging area digunakan untuk memudahkan melakukan transaksi dan pembersihan data sehingga dapat menghasilkan data yang berkuliatas. Karena di dalam staging area terdapat proses untuk penggabungan data, pembersihan (cleansing) data dan standarisasi data.

\subsection{Data Mart}

Menurut Inmon (2005) data mart adalah subset dari data warehouse yang umumnya terdiri dari sebuah subjek tunggal. Jadi, data mart merupakan serangkaian data yang hanya menjelaskan satu fungsi dari operasi perusahaan. Data mart menjadi pilihan solusi ketika kecepatan pengembangan dan pembuktian konsep menjadi prioritas (Ponniah, 2010).

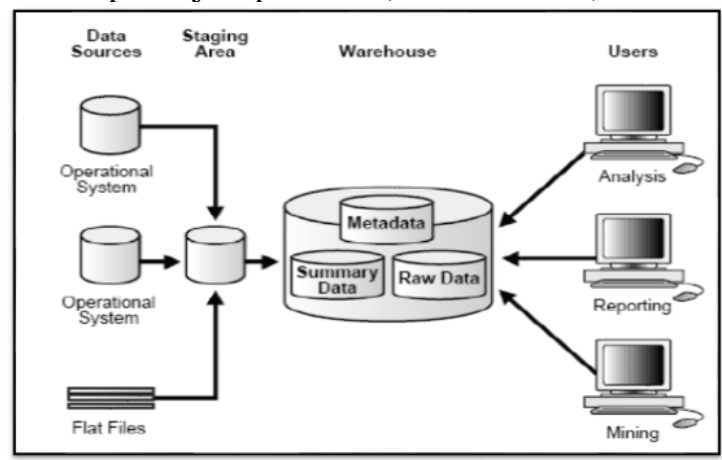

Gambar 2. Proses perumusan data (Inmon, 2005)

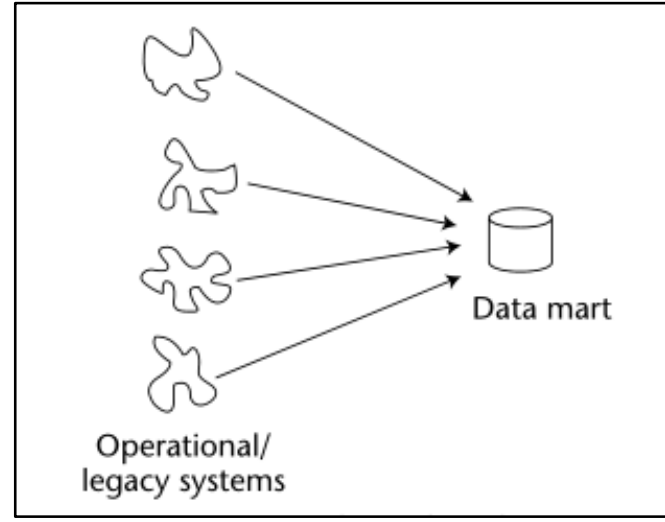

Gambar 3. Data Mart dan sistem operasional dan legacy (Inmon, 2005)

Masih menurut Ponniah (2010), resiko kegagalan dari data mart adalah kecil, sehingga memudahkan ketika diimplementasikan untuk riset. Secara umum, data mart dapat langsung menampung data dari sistem operasional dan legacy seperti digambarkan pada gambar 3 .

\subsection{Dashboard System}

Salah satu bentuk aplikasi komputer yang umum digunakan dalam mendukung pengambilan keputusan adalah dashboard system. Menurut Few (2006), dashboard pada dasarnya adalah nama baru untuk Executive Information System yang dikembangkan pertama kali pada tahun 1980an. Pada awal pengembangannya, dashboard mengalami fase hibernasi disebabkan karena metode pendukung penyediaan datanya yaitu data warehousing dan business intelligence belum berevolusi untuk menyediakan metodologi penanganan datanya. Hibernasi ini berlangsung sampai ketika metodologi data warehousing dan business intelligence menjadi cukup matang di tahun 2000an. (Few, 2006).

Setelah melalui serangkaian penelitian, Few (2006) kemudian mendefinisikan dashboard sebagai sebuah tampilan visual dari informasiinformasi penting yang dibutuhkan untuk mencapai satu tujuan atau lebih. Tampilan tersebut dikonsolidasikan dan ditata dalam satu layar sehingga informasi yang ada dapat dimonitor dalam satu kali lihat.

\section{Poin-poin Penting Dashboard System}

Beberapa poin penting yang perlu diperhatikan kaitannya dengan dashboard (Few, 2006) adalah:

1. Dashboard adalah tampilan visual. Informasi pada dashboard dipresentasikan secara visual, biasanya sebagai kombinasi dari teks dan grafik, tetapi dengan penekanan pada grafik. Dashboard menggunakan grafik secara intensif, bukan karena itu cantik, tetapi karena representasi grafik yang ditangani secara ahli dapat menyampaikan maksud 
secara lebih efisien dan lebih kaya daripada hanya menggunakan teks.

2. Dashboard menampilkan informasi yang dibutuhkan untuk mencapai tujuan bisnis yang spesifik. Untuk mencapai sebuah tujuan seringkali memerlukan akses terhadap koleksi informasi yang tidak berelasi, tersebar dalam beragam sumber yang berhubungan dengan fungsi bisnis yang bervariasi.

3. Sebuah dashboard cukup untuk ditampilkan dalam satu tampilan layar. Informasi yang ada harus dicukupkan dalam satu layar, secara menyeluruh tersedia dalam jangkauan pandangan mata pengguna dalam satu kali lihat.

4. Dashboard digunakan untuk memonitor informasi dalam satu kali lihat. Mengesampingkan fakta bahwa informasi mengenai hampir apa saja dapat ditampilkan dalam sebuah dashboard, ada setidaknya satu karakteristik yang mendeskripsikan hampir semua informasi yang ditemukan dalam dashboard-dashboard yang sudah ada, yaitu bahwa informasi-informasi tersebut disingkat dalam sebuah bentuk rangkuman atau perkecualian.

Selain poin-poin penting tersebut, menurut Few (2006) yang perlu juga diperhatikan agar dashboard dapat melakukan pekerjaannya secara efektif :

1. Dashboard mempunyai mekanisme tampilan yang kecil, padat, jelas dan intuitif. Gunakan tampilan yang sesuai untuk tiap jenis informasi yang perlu untuk ditampilkan, dan tidak harus dengan tampilan fuel gauge, traffic signal atau thermometer.

2. Dashboard dibuat menurut pesanan sesuai kebutuhan pengguna. Informasi yang ada pada dashboard harus dibuat secara spesifik terhadap kebutuhan dari pengguna, kelompok atau fungsi bisnis, karena apabila tidak, dashboard akan gagal menjalankan tugasnya.

\subsubsection{Kesalahan Umum dalam Pembuatan Dashboard System}

Menurut Few (2006), beberapa kesalahan yang umum terjadi dalam pembuatan dashboard system adalah :

1. Melebihi batasan dari satu layar

2. Penyediaan konteks yang kurang memadai untuk data

3. Penampilan detil atau presisi yang berlebihan

4. Penunjuk ukuran yang tidak langsung

5. Pemilihan media tampilan yang tidak sesuai

6. Perkenalan variasi yang tidak berarti

7. Penggunaan desain media tampilan yang buruk

8. Penyandian data kuantitatif yang tidak tepat
9. Penataan data yang buruk

10. Penggarisbawahan data penting yang tidak efektif

11. Tampilan yang kacau karena dekorasi yang tidak berguna

12. Penggunaan warna yang tidak tepat atau berlebihan

13. Mendisain tampilan visual yang tidak menarik

\section{HASIL dan PEMBAHASAN}

Hasil dan pembahasan dari penelitian ini meliputi rancang bangun data mart yang dilanjutkan dengan dashboard system. Dashboard yang dibangun pada penelitian ini memiliki tiga tampilan utama yaitu tampilan login, utama dashboard, indikator dan chart detil.

\subsection{Rancang Bangun Data Mart}

Penelitian ini menggunakan data mart dengan pertimbangan bahwa data mart lebih mudah diimplementasikan dan mempunyai resiko kegagalan lebih kecil. Dalam pembuatan data mart diperlukan beberapa tahap agar data mart menjadi terstruktur. Tahap perancangan data mart yang digunakan pada penulisan ini, yaitu:

1. Memilih proses (Choosing the proceess)

Proses (fungsi) mengacu pada subyek masalah dari data mart tertentu. Data mart yang akan dibangun harus sesuai anggaran dan dapat menjawab masalah-masalah bisnis yang penting.

2. Memilih Grain (Choosing the Grain)

Grain merupakan data dari calon fakta yang dapat dianalisis.

3. Rancangan matriks

Rancangan matriks struktur untuk data mart akademik Prodi S1 SI disesuaikan dengan hasil analisis kebutuhan. Kemudian rancangan matriks tersebut (Tabel 1) digunakan untuk dasar membuat struktur data mart.

Tabel 1. Rancangan matriks struktur data mart

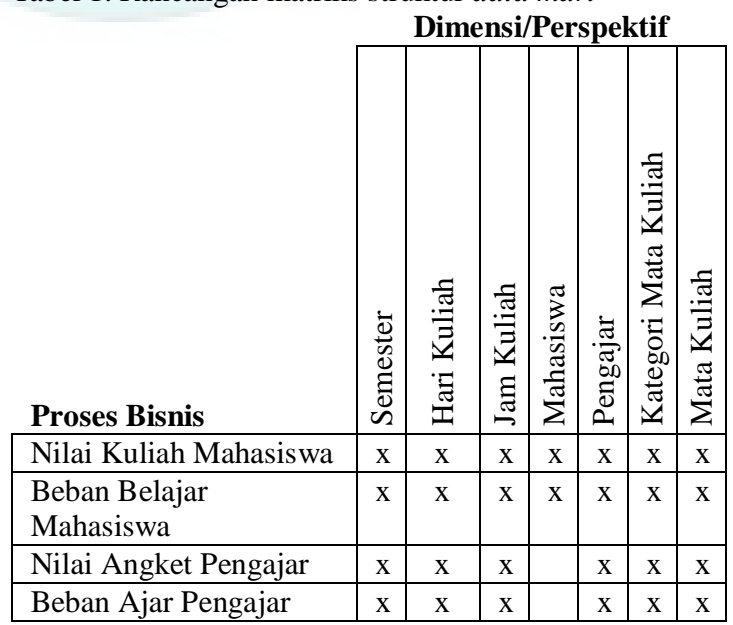


Jatmika, dkk., Rancang Bangun Data Mart dan Purwarupa Dashboard untuk Visualisasi Performa..

4. Memilih Fakta (Choosing the facts) Memilih fakta yang digunakan dalam data mart. Masing-masing fakta memiliki data yang dapat dihitung, untuk selanjutnya ditampilkan dalam bentuk laporan, grafik atau berbagai macam diagram. Berikut ini fakta-fakta yang akan ditampilkan di data mart:

a. Nilai Kuliah Mahasiswa, meliputi nilai angka, nilai huruf, dan bobot nilai huruf

b. Beban Belajar Mahasiswa, meliputi beban sks mahasiswa, dan banyak kelas mahasiswa.

c. Nilai Angket Pengajar, meliputi indeks kepuasan terhadap pengajar.

d. Beban Ajar Pengajar, meliputi beban sks pengajar, banyak kelas pengajar, dan total mahasiswa kelas.

5. Melengkapi Tabel Dimensi (Rounding out the dimension tables)

Menambahkan sebanyak mungkin deskripsi teks pada tabel dimensi. Deskripsi tersebut harus intuitif dan dapat dimengerti oleh user. Tabel 2 berikut ini merupakan deskripsi teks dari tabel dimensi.

Tabel 2. Tabel Rounding Out Dimensions

\begin{tabular}{|c|c|c|}
\hline Dimensi & Field & Deskripsi \\
\hline Waktu & $\begin{array}{l}\text { Semester } \\
\text { Hari } \\
\text { Jam }\end{array}$ & $\begin{array}{l}\text { Laporan dapat } \\
\text { ditinjau berdasarkan } \\
\text { semester, } \\
\text { berdasarkan hari, } \\
\text { dan berdasarkan jam } \\
\text { pelaksanaan } \\
\text { perkuliahan. }\end{array}$ \\
\hline Pengajar & Pengajar & $\begin{array}{l}\text { Laporan dapat } \\
\text { ditinjau berdasarkan } \\
\text { pengajar tertentu. }\end{array}$ \\
\hline Mata & Mata kuliah & Laporan dapat \\
\hline kuliah & $\begin{array}{l}\text { Kategori } \\
\text { Mata Kuliah }\end{array}$ & $\begin{array}{l}\text { ditinjau berdasarkan } \\
\text { mata kuliah, dan } \\
\text { kategori mata kuliah } \\
\text { tertentu. }\end{array}$ \\
\hline Mahasiswa & $\begin{array}{l}\text { Mahasiswa } \\
\text { Angkatan } \\
\text { Mahasiswa }\end{array}$ & $\begin{array}{l}\text { Laporan dapat } \\
\text { ditinjau berdasarkan } \\
\text { angkatan mahasiswa } \\
\text { tertentu. }\end{array}$ \\
\hline
\end{tabular}

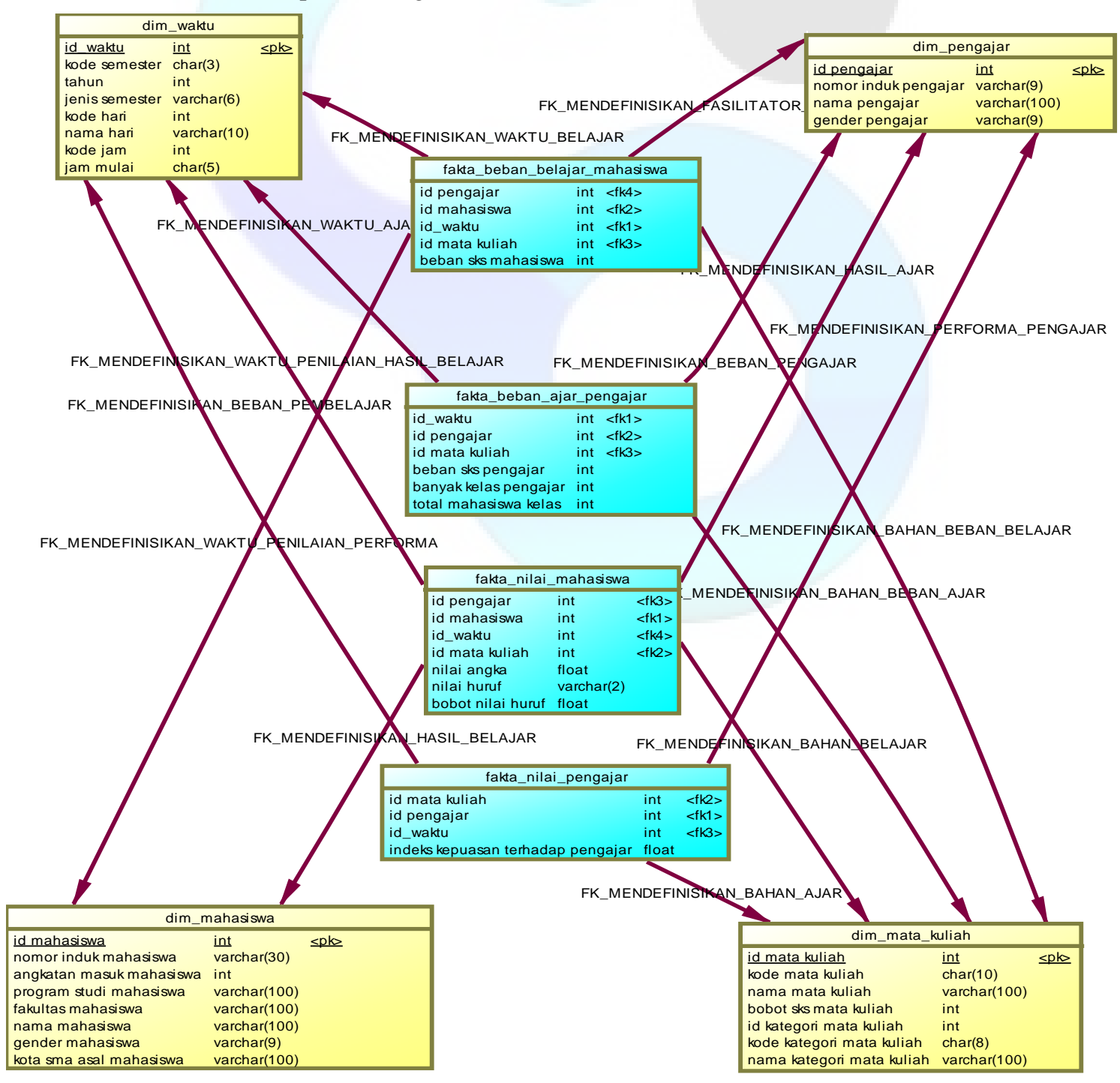

Gambar 5. Skema konstelasi data mart akademik 


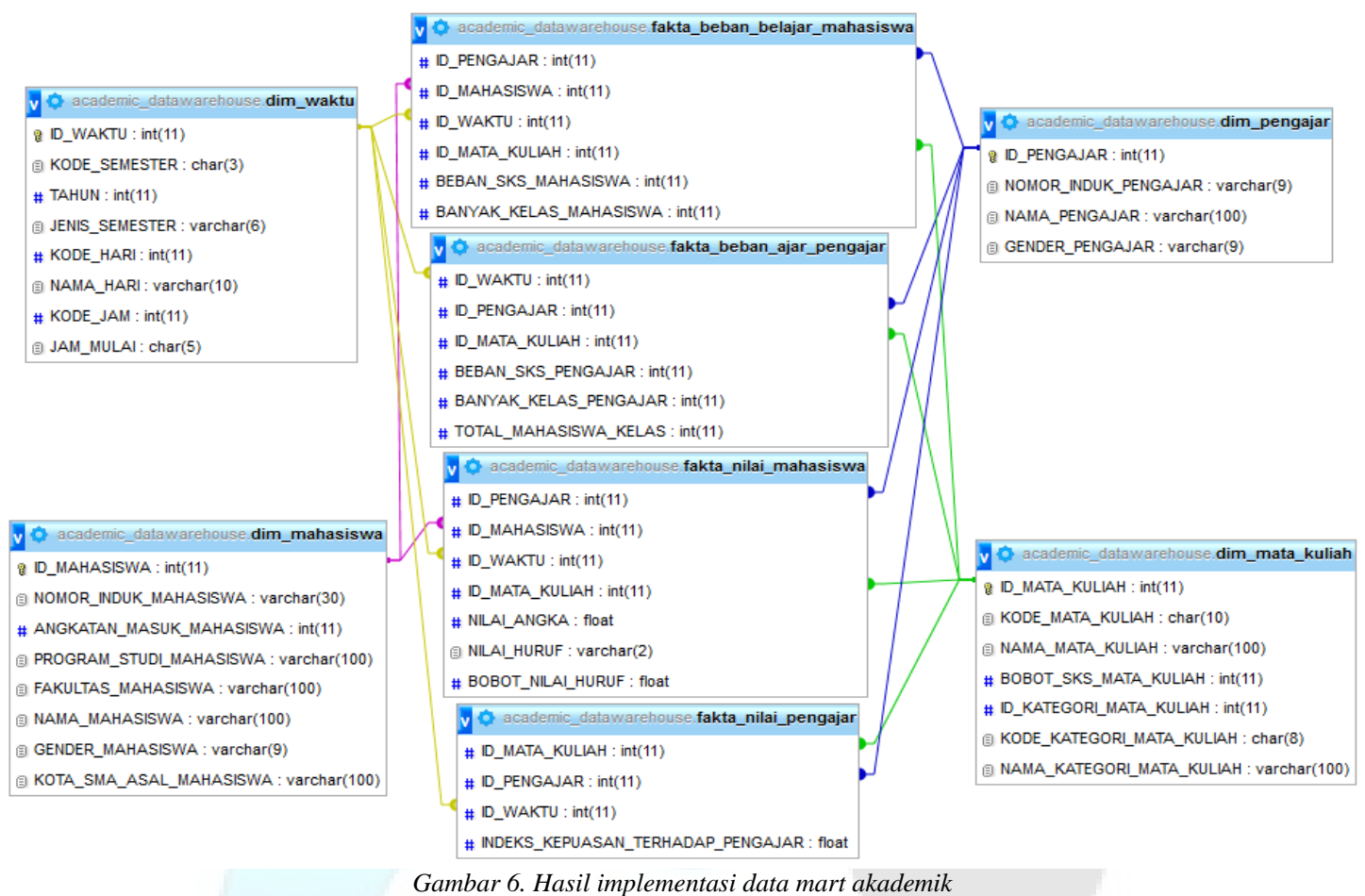

Pada perancangan ini, bentuk skema yang dipilih adalah skema bintang (star schema), karena skema ini merupakan skema yang mudah dipahami pengguna daripada skema lain, mengoptimasi navigasi, dan paling cocok digunakan untuk query (Ponniah, 2010). Bentuknya yang tidak terlalu rumit, memudahkan dalam hal query untuk menghasilkan data yang akan divisualisasikan dalam bentuk dashboard. Skema konstelasinya dapat dilihat pada Gambar 5, sedangkan hasil implementasinya dapat dilihat pada Gambar 6.

Data mart ini terdiri dari 4 tabel fakta dan 4 tabel dimensi berbagi (shared). Struktur ini kemudian dijadikan target proses ETL dan sumber data untuk dashboard visualisasi.

\subsection{Rancang Bangun Dashboard System}

Pembuatan Purwarupa Tampilan Front-End

Pembuatan purwarupa tampilan front-end dimaksudkan agar sistem yang dibuat dapat segera berwujud untuk memudahkan pembuat sistem otentikasi dan melakukan perancangan layout dasar dashboard. Purwarupa yang dibuat dapat dilihat pada bagian A sampai dengan $\mathrm{C}$.

\section{A. Tampilan Login}

Tampilan login diperlukan di dalam sistem sebagai pintu gerbang sebelum pengguna dapat mengakses informasi pada dashboard system. Hal ini disebabkan data pada dashboard bersifat sensitif dan tidak boleh diakses sembarang orang. Hasil implementasi tampilan login dapat dilihat pada gambar 7 .

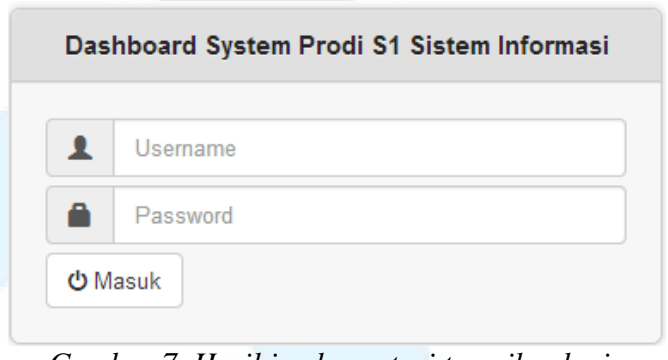

Gambar 7. Hasil implementasi tampilan login

\section{B. Tampilan Utama Dashboard}

Tampilan utama dashboard didesain agar pengguna dapat melihat indikator-indikator utama akademik dalam satu kali lihat. Tampilan utama ini juga harus didesain sedemikian rupa agar informasi yang penting berada pada posisi lihat yang pas dan tidak terabaikan. Secara umum, layout dari tampilan utama dashboard dapat dilihat pada gambar 4.29. Tampilan ini dijalankan ada monitor dengan resolusi 1366x768 pixel dengan browser yang digunakan adalah Opera.

\section{Dimensi Indikator Dashboard}

Dalam penelitian ini, ada dua jenis kelompok dimensi indikator, yaitu mahasiswa dan pengajar. Masing-masing kemudian didetilkan lagi menjadi beberapa indikator turunan yaitu :

1. Indeks Prestasi Mahasiswa

2. SKS Belajar Mahasiswa

3. Kelas Belajar Mahasiswa

4. Indeks Kepuasan Pengajar

5. SKS Ajar Pengajar

6. Kelas Ajar Pengajar 
Jatmika, dkk., Rancang Bangun Data Mart dan Purwarupa Dashboard untuk Visualisasi Performa..

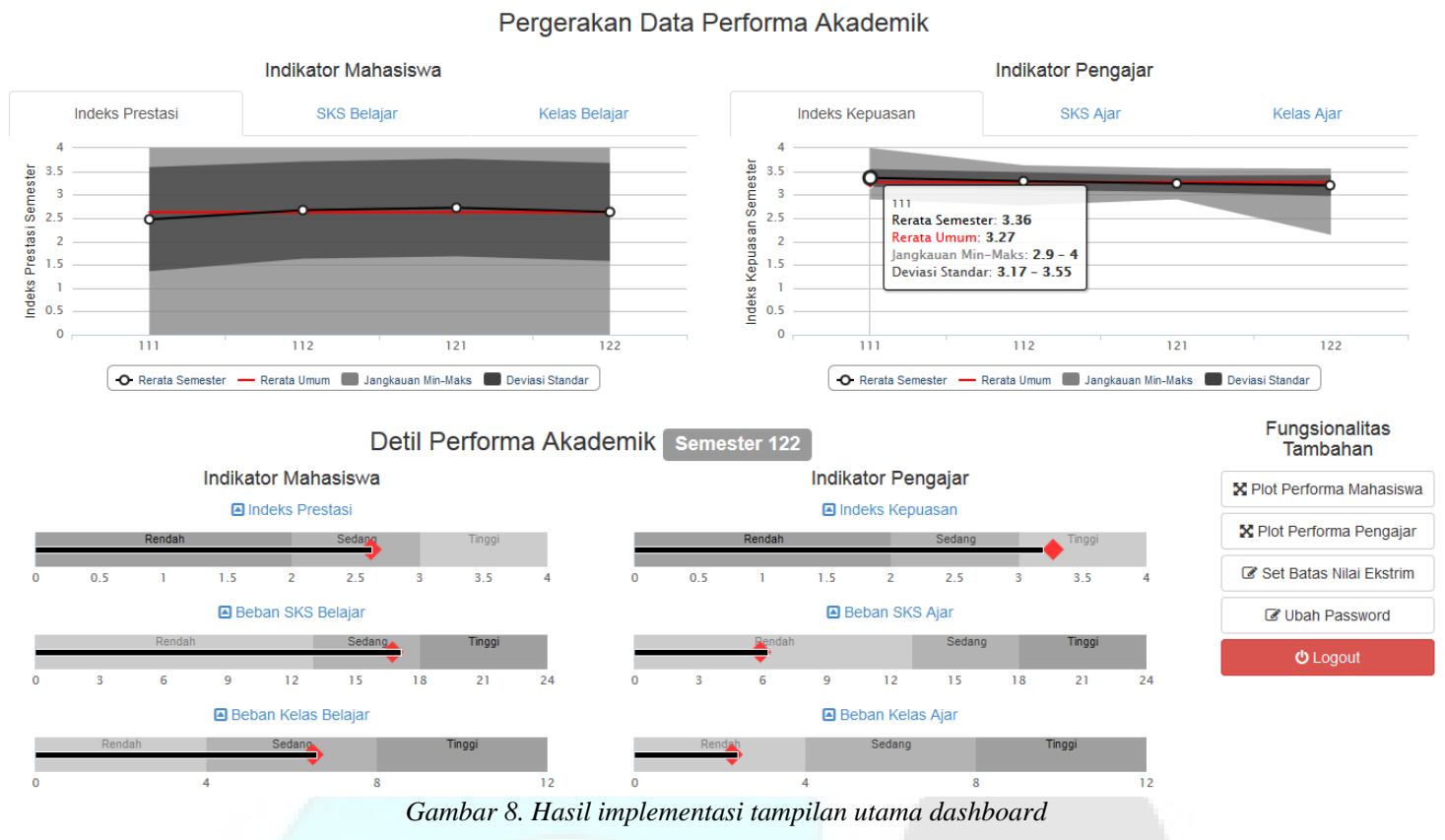

Seperti yang terlihat pada Gambar 8, bahwa tiap segmen di tampilan utama dashboard akan berisi chart-chart yang dibutuhkan untuk kebutuhan visualisasi informasi indikator turunan tersebut. Chart-chart tersebut akan dijelaskan pada bagian C.1 sampai dengan C.3.

\section{C.1. Chart Indikator}

Tiap indikator turunan akan divisualisasikan agar pergerakannya pada semester yang sudah berjalan (semester divisualkan dalam sumbu X). Chart yang dipilih adalah gabungan antara line chart dan area chart (yang mengiringi line chart) untuk menggambarkan :

1. Rata-rata pencapaian indikator per semester (garis hitam tebal).

2. Rata-rata pencapaian indikator seluruh semester sebagai baseline umum (garis merah tebal).

3. Deviasi standar persebaran data (area abuabu gelap).

4. Jangkauan minimum-maksimum data (area abu-abu terang).

Contoh hasil implementasinya dapat dilihat pada gambar 9 .

\section{C.2. Chart Detil Data \& Komparasi Baseline}

Pencapaian tiap poin indikator setiap semester kemudian perlu dibandingkan dengan baseline rata-rata umumnya, untuk itu perlu dibuat chart bertipe bullet. Bullet chart ini mempunyai kelebihan, bahwa walaupun sederhana namun telah mampu menggambarkan beberapa hal yang penting, yaitu :

1. Rendah, sedang, atau tingginya suatu pencapaian indikator (area abu-abu gelap, area abu-abu sedang, dan area abu-abu terang yang bertumpuk [stacked])

2. Pencapaian rata-rata indikator semester terfokus (diagram batang berwarna hitam)

3. Pencapaian rata-rata-indikator seluruh semester (bangun persegiempat berwarna merah)

Dengan ditampilkannya gambaran rata-rata indikator semester terfokus \& rata-rata indikator seluruh semester maka akan memudahkan pengguna melihat apakah di semester tersebut baseline sebuah indikator sudah tercapai atau tidak. Hasil implementasi chart-nya dapat dilihat pada Gambar 10 untuk detil data semester 112 dan Gambar 11 untuk detil data semester 121.

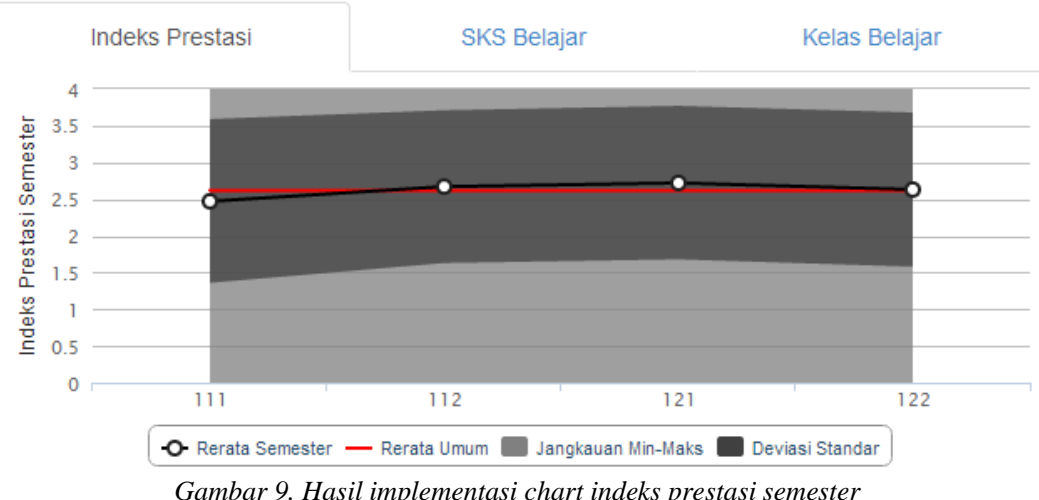


Jurnal Sistem Informasi, Volume 5, Nomor 3, Maret 2015, 281-291

\section{Detil Performa Akademik Semester 112}
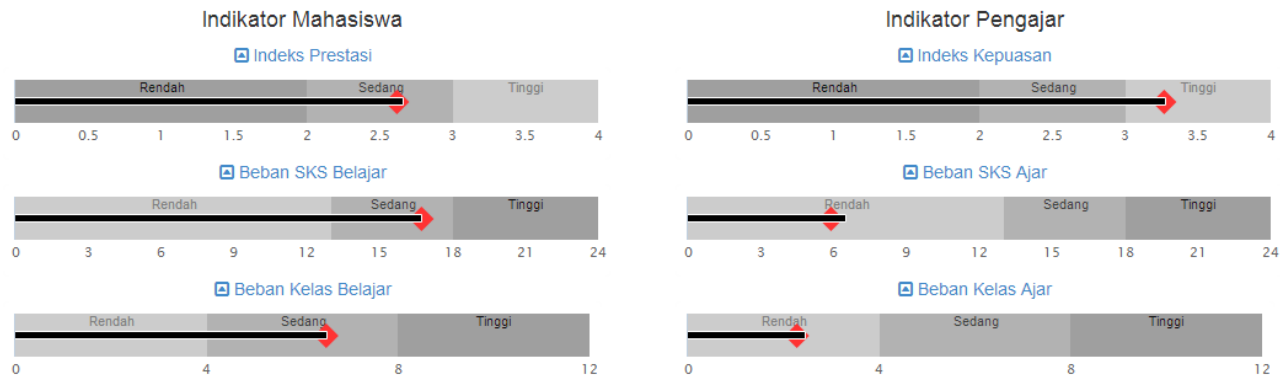

Gambar 10. Hasil implementasi chart detil data semester 112

Detil Performa Akademik Semester 121

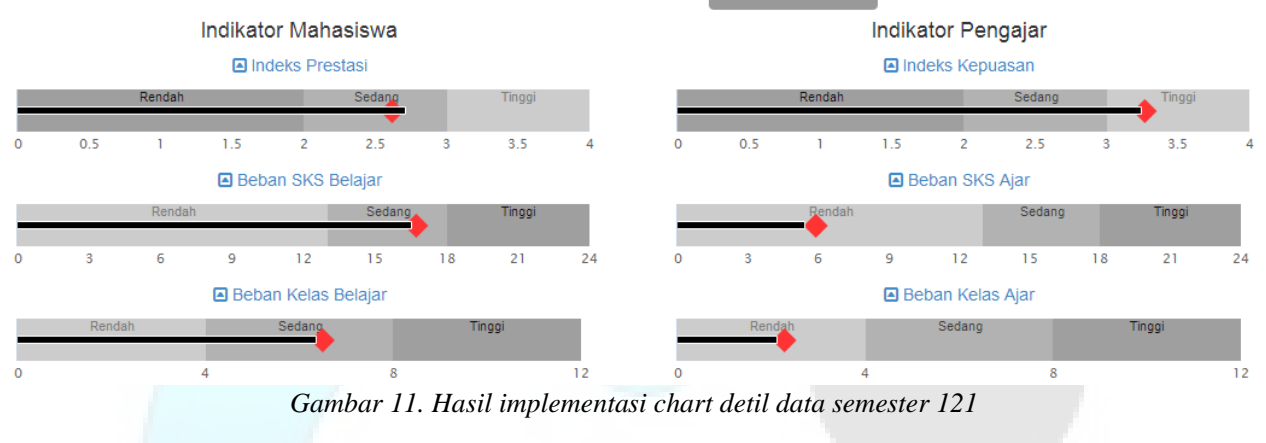

Set Nilai Baseline Parameter Akademik

\begin{tabular}{|c|c|c|c|}
\hline \multicolumn{2}{|c|}{ Parameter Mahasiswa } & \multicolumn{2}{|c|}{ Parameter Pengajar } \\
\hline batas bawah ips mahasiswa & 1.87 & batas bawah ips pengajar & 3 \\
\hline batas atas ips mahasiswa & 3.5 & batas atas ips pengajar & 3.5 \\
\hline batas bawah sks mahasiswa & 4 & batas bawah sks pengajar & 3 \\
\hline batas atas sks mahasiswa & 23 & batas atas sks pengajar & 13 \\
\hline batas bawah kelas mahasiswa & 2 & batas bawah kelas pengajar & 2 \\
\hline batas atas kelas mahasiswa & 8 & batas atas kelas pengajar & 6 \\
\hline
\end{tabular}

Gambar 12. Hasil implementasi tampilan pengubahan batas nilai ekstrim indikator Tabel Nilai Esktrim Indeks Prestasi Semester 122 | Gexport Data

\begin{tabular}{|c|c|c|c|c|}
\hline \multicolumn{4}{|c|}{ BAWAH $[<1.87]$} & \\
\hline Show 10 & - entries & Filter: & & \\
\hline No. & $\Delta \mathrm{NIM}$ & & IPS & $\approx$ \\
\hline 1 & 04410100033 & & 0.00 & \\
\hline 2 & 04410100073 & & 0.00 & \\
\hline 3 & 04410100083 & & 0.00 & \\
\hline 4 & 05410100136 & & 0.00 & \\
\hline 5 & 05410100137 & & 0.00 & \\
\hline 6 & 05410100147 & & 0.00 & \\
\hline 7 & 06410100009 & & 0.00 & \\
\hline 8 & 06410100062 & & 0.00 & \\
\hline 9 & 06410100155 & & 0.00 & \\
\hline 10 & 06410100158 & & 0.00 & \\
\hline
\end{tabular}

\begin{tabular}{|c|c|c|c|}
\hline \multicolumn{4}{|c|}{$\operatorname{ATAS}[>3.5]$} \\
\hline Show 10 & $\nabla$ entries & Filter: & \\
\hline No. & NIM & & IPS \\
\hline 1 & 04410100005 & & 3.54 \\
\hline 2 & 08410100120 & & 3.54 \\
\hline 3 & 04410100086 & & 3.56 \\
\hline 4 & 05410100001 & & 3.56 \\
\hline 5 & 06410100157 & & 3.56 \\
\hline 6 & 06410100195 & & 3.56 \\
\hline 7 & 07410100023 & & 3.56 \\
\hline 8 & 07410100156 & & 3.56 \\
\hline 9 & 08410100012 & & 3.56 \\
\hline 10 & 08410100054 & & 3.56 \\
\hline
\end{tabular}

Gambar 13. Tabel nilai ekstrim Indeks Prestasi Mahasiswa semester 122 
Jatmika, dkk., Rancang Bangun Data Mart dan Purwarupa Dashboard untuk Visualisasi Performa..

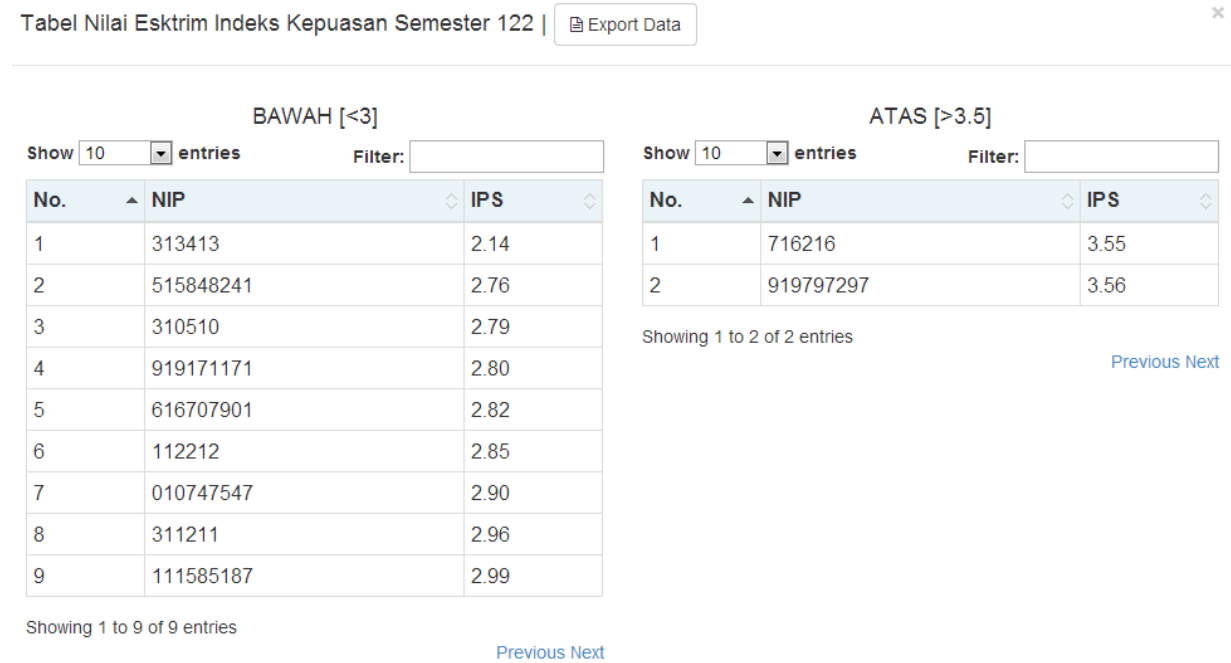

Gambar 14. Tabel nilai ekstrim Indeks Kepuasan Pengajar semester 122

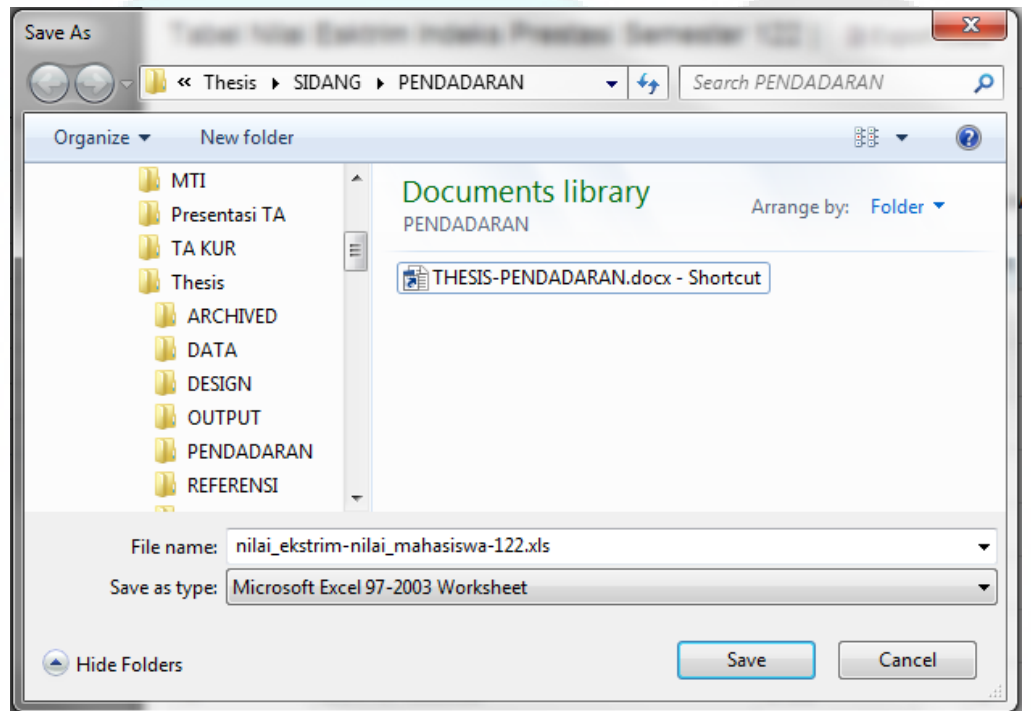

Gambar 15. Proses simpan file export nilai ekstrim Indeks Prestasi Mahasiswa

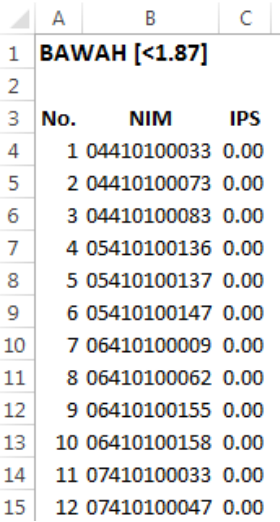

Gambar 16. Isi file export nilai ekstrim Indeks Prestasi mahasiswa

\section{C.3. Fasilitas Penanganan Nilai Ekstrim}

Seringkali kaprodi S1 SI kesulitan untuk mengindentifikasi mahasiswa atau pengajar yang indikatornya di bawah maupun yang di atas standar (bernilai ekstrim bawah maupun atas). Dalam sistem yang dibangun, hal ini kemudian difasilitasi dengan:

1. Tampilan pengubahan nilai batas ekstrim indikator (Gambar 12).

2. Tampilan pelaporan nilai ekstrim (Gambar 13 dan Gambar 14).

Fasilitas export nilai ekstrim (Gambar 15 dan Gambar 16).

Uji Kemampuan Dashboard System Visualisasi Informasi Performa Akademik

Uji kemampuan dashboard system dalam visualisasi informasi performa akademik dilakukan untuk melihat sejauh mana sistem dapat membaca, menerjemahkan dan memvisualisasikan data yang sudah tersimpan dalam data mart. Hasil pengujiannya dapat dilihat pada Tabel 3 . 
Tabel 3. Tabel Hasil Implementasi Visualisasi Performa Akademik

\begin{tabular}{|c|c|c|}
\hline $\begin{array}{c}\text { Poin } \\
\text { Pengujian }\end{array}$ & Output Harapan & $\begin{array}{l}\text { Output Hasil } \\
\text { Implementasi }\end{array}$ \\
\hline $\begin{array}{l}\text { Tampilan } \\
\text { Timeline } \\
\text { Parameter } \\
\text { Utama }\end{array}$ & $\begin{array}{l}\text { Sistem dapat } \\
\text { menampilkan } \\
\text { timeline pergerakan } \\
\text { rata-rata nilai untuk } \\
\text { parameter utama } \\
\text { yang meliputi : } \\
\text { 1. Indeks Prestasi } \\
\text { Mahasiswa } \\
\text { 2. SKS Belajar } \\
\text { Mahasiswa } \\
\text { Kelas Belajar } \\
\text { 3. Mahasiswa } \\
\text { 4. Indeks } \\
\text { Kepuasan } \\
\text { Pengajar } \\
\text { 5KS Ajar } \\
\text { Pengajar } \\
\text { Kelas Ajar } \\
\text { 6. Pengajar }\end{array}$ & $\begin{array}{l}\text { Sistem sudah } \\
\text { dapat } \\
\text { menampilkan } \\
\text { timeline } \\
\text { pergerakan rata- } \\
\text { rata nilai untuk } \\
\text { parameter utama. } \\
\text { Dapat dilihat pada } \\
\text { 1. Gambar } 9 \\
\text { 2. Gambar } 10 \\
\text { 3. Gambar } 11 \\
\text { 4. Gambar } 12 \\
\text { 5. Gambar } 13 \\
\text { 6. Gambar } 14\end{array}$ \\
\hline $\begin{array}{l}\text { Tampilan } \\
\text { Detil } \\
\text { Parameter } \\
\text { Utama } \\
\text { Berdasarkan } \\
\text { Semester }\end{array}$ & $\begin{array}{l}\text { Sistem dapat } \\
\text { menampilkan detil } \\
\text { rata-rata nilai untuk } \\
\text { parameter utama } \\
\text { berdasarkan } \\
\text { semester. Diambil } \\
\text { sampel semester } \\
112 \text { dan } 121 .\end{array}$ & $\begin{array}{l}\text { Sistem sudah } \\
\text { dapat } \\
\text { menampilkan } \\
\text { detil rata-rata nilai } \\
\text { untuk parameter } \\
\text { utama } \\
\text { berdasarkan } \\
\text { semester. Dapat } \\
\text { dilihat pada : } \\
\text { Gambar } 15 \text { untuk } \\
\text { sampel semester } \\
112 \text {, dan Gambar } \\
16 \text { untuk sampel } \\
\text { semester } 121\end{array}$ \\
\hline
\end{tabular}

Uji Kemampuan Dashboard System Menyajikan Nilai Ekstrim Parameter

Uji kemampuan dashboard system dalam menyajikan nilai ekstrim parameter dilakukan untuk melihat sejauh mana sistem dapat melakukan setting batas nilai ekstrim \& melakukan penyajian nilai ekstrim tersebut dalam bentuk tabel display maupun worksheet. Hasil pengujiannya dapat dilihat pada Tabel 4.

Tabel 4 Tabel Hasil Implementasi Penyajian Nilai Ekstrim Parameter

\begin{tabular}{lll}
\hline $\begin{array}{c}\text { Poin } \\
\text { Pengujian }\end{array}$ & Output Harapan & $\begin{array}{c}\text { Output Hasil } \\
\text { Implementasi }\end{array}$ \\
\hline Tampilan Set & Sistem dapat & Sistem sudah \\
Nilai Baseline & menampilkan & dapat \\
Parameter & baseline lama dan & menampilkan \\
Akademik & memfasilitasi & baseline lama dan \\
& pengubahan nilai & memfasilitasi \\
& baseline tersebut. & pengubahan nilai \\
& & baseline tersebut. \\
& & Dapat dilihat pada \\
gambar 17.
\end{tabular}

\begin{tabular}{|c|c|c|}
\hline $\begin{array}{l}\text { Penyajian } \\
\text { Nilai Ekstrim } \\
\text { dalam bentuk } \\
\text { tabel display }\end{array}$ & $\begin{array}{l}\text { Sistem dapat } \\
\text { menampilkan } \\
\text { nilai ekstrim } \\
\text { dalam bentuk } \\
\text { tampilan web. }\end{array}$ & $\begin{array}{l}\text { Sistem sudah } \\
\text { dapat } \\
\text { menampilkan } \\
\text { nilai ekstrim } \\
\text { dalam bentuk } \\
\text { tampilan web. } \\
\text { Dapat dilhat pada } \\
\text { gambar } 18 \text { dan } 19 .\end{array}$ \\
\hline $\begin{array}{l}\text { Penyajian } \\
\text { Nilai Ekstrim } \\
\text { dalam bentuk } \\
\text { tabel } \\
\text { worksheet }\end{array}$ & $\begin{array}{lr}\text { Sistem dapat } \\
\text { melakukan } \\
\text { eksport nilai } \\
\text { ekstrim dalam } \\
\text { bentuk worksheet } \\
\text { Microsoft Excel. }\end{array}$ & 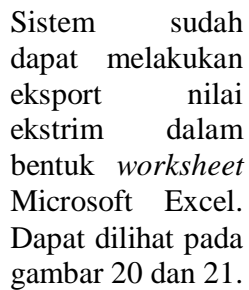 \\
\hline
\end{tabular}

Uji Penerimaan Pengguna

Analisis uji penerimaan pengguna dilakukan dengan melakukan penyebaran angket yang bertujuan untuk mengukur respon pengguna kepada pihak-pihak yang berkepentingan terhadap sistem pendukung keputusan yang dibuat dalam penelitian ini. Berdasarkan wawancara dengan Kepala Program Studi S1 Sistem Informasi, maka pihak-pihak yang ditunjuk untuk diberi angket adalah : Kepala Program Studi S1 Sistem Informasi, Sekretaris Program Studi S1 Sistem Informasi, dan Kepala Bagian Laboratorium Komputer. Tiga kriteria utama yang diuji dalam angket respon:

1. Tampilan Sistem,

2. Penggunaan Sistem, dan

3. Informasi yang Ditampilkan Sistem

Berdasarkan respon dari pengguna yang telah didapatkan, maka kemudian harus dilakukan analisis terhadap penerimaan pengguna. Untuk itu, perlu dilakukan penskalaan. Sangat Kurang (-2), Kurang (-1), Cukup (0), Baik (1), Sangat Baik (2).

Tabel 5. Tabel rangkuman hasil kuesioner

\begin{tabular}{|c|c|c|c|c|c|}
\hline \multirow{2}{*}{ Kriteria } & \multicolumn{5}{|c|}{ Hasil } \\
\hline & 1 & 2 & 3 & 4 & 5 \\
\hline Tampilan Sistem & & 1 & 4 & 7 & \\
\hline Penggunaan Sistem & & & 3 & 10 & 5 \\
\hline $\begin{array}{l}\text { Informasi yang } \\
\text { ditampilkan sistem }\end{array}$ & & & 2 & 3 & 10 \\
\hline $\begin{array}{ll}\text { 1. Sangat Kurang } & \text { 2. Kurang } \\
\text { 5. Sangat Baik } & \end{array}$ & & & & & \\
\hline
\end{tabular}

Rekap hasil secara keseluruhan untuk tiap kriteria adalah seperti pada Tabel 5. Analisis untuk hasil tersebut adalah sebagai berikut:

1. Tampilan Sistem

Bobot skala untuk tampilan program adalah: $(1 \mathrm{x}-1+4 \mathrm{x} 0+7 \mathrm{x} 1) / 12=0,5$

Penilaian untuk tampilan program oleh pengguna adalah cukup mendekat baik. Berarti pengguna menerima dengan baik tampilan program yang diimplementasikan.

2. Penggunaan Sistem 
Jatmika, dkk., Rancang Bangun Data Mart dan Purwarupa Dashboard untuk Visualisasi Performa..

Bobot skala untuk penggunaan program adalah: $(3 \times 0+10 \times 1+5 \times 2) / 18=1,111$

Hasil penilaian untuk penggunaan program oleh pengguna cukup jelas, yaitu baik. Dapat disimpulkan bahwa pengguna tidak mengalami kesulitan dalam pengoperasian program.

3. Informasi yang Ditampilkan Sistem

Bobot skala untuk tampilan program adalah: $(2 \times 0+3 \times 1+10 \times 2) / 15=1,533$

Hasil penilaian untuk kriteria ini juga cukup jelas, yaitu sangat baik. Karena kriteria ini merupakan poin penilaian pengguna yang terpenting, dan hasilnya sangat baik, maka kemampuan sistem menyampaikan informasi yang dibutuhkan pengguna dapat dinyatakan sudah sangat baik.

\section{SIMPULAN dan SARAN}

Simpulan yang didapatkan dari penelitian rancang bangun data mart dan purwarupa dashboard untuk visualisasi performa akademik ini adalah :

1. Desain star schema mendukung proses rancang bangun data mart akademik. Desain star schema juga memudahkan proses rancang bangun dashboard system Prodi S1 Sistem Informasi STIKOM Surabaya dalam hal kemudahan .

2. Berdasarkan evaluasi kebergunaan terhadap hasil rancang bangun sistem pendukung keputusan yang telah dibuat, dapat dinyatakan bahwa :

a. Pengguna menerima dengan baik tampilan program yang diimplementasikan,

b. Pengguna tidak mengalami kesulitan dalam pengoperasian program, dan

c. Kemampuan sistem menyampaikan informasi yang dibutuhkan pengguna dapat dinyatakan sudah sangat baik.

Hal-hal yang mungkin dikembangkan dan diperbaiki dari penelitian ini adalah :

1. Tinjauan ulang terhadap efisiensi model data mart yang dihasilkan, terutama dalam hal penggunaan $C P U$ time pada saat proses pembacaan data.

2. Dashboard system yang telah dikembangkan dalam bentuk aplikasi web dapat dikembangkan ke arah aplikasi mobile dan web services sehingga dapat menunjang mobilitas Kepala Program Studi S1 Sistem Informasi.

3. Pengaplikasian data dimensi (yang sebenarnya sudah tersimpan dalam data mart) untuk menambah drilldown level dalam dashboard system untuk menunjang proses eksplorasi Kepala Program Studi S1 Sistem Informasi. Misalnya data hari \& jam proses belajar di tabel dimensi waktu, dan gender pengajar di tabel dimensi pengajar.

4. Penerapan analisis lanjutan untuk menggambarkan hubungan antar data. Misalnya: analisis what-if scenario atau analisis regresi linear.

\section{DAFTAR RUJUKAN}

Connolly, T., Begg, C., 2001. Database Systems : A Practical Approach to Design, Implementation, and Management. 3rd ed. Boston, MA: Addison Wesley.

Few, S., 2006. Information Dashboard Design: The Effective Visual Communication of Data. O'Reilly.

Ghaseminejad, A. H.; Brantingham, P., 2010. An Executive Decision Support System For Longitudinal Statistical Analysis of Crime and Law Enforcement Performance. Intelligence and Security Informatics (ISI), 2010 IEEE International Conference, 1, pp.1-6.

Inmon, W.H., 2005. Building Data warehouse. 4th ed. New York, NY:John Wiley\& Sons.

Marakas, G. M., 2003. Modern Data Warehousing, Mining and Visualization : Core Concepts. Englewood Cliffs, NJ: Prentice-Hall.

Paunica, M., Matac, M.L., Manole, A.L., Motofei, C., 2010. Measuring the Performance of Educational Entities with a Data Warehouse. Annales Universitatis Apulensis Series Oeconomica, 12(1), pp.176-184.

Ponniah, P., 2010. Data Warehousing Fundamentals. 2nd ed. New York, NY: John Wiley \& Sons.

Prasetija, H.P., 2010. Purwarupa Data warehouse Pada Sistem Informasi Manajemen Perguruan Tinggi, Studi Kasus STIKOM Surabaya. Master. Institut Teknik Sepuluh Nopember Surabaya.

Prasetyo, E., 2011. Perancangan Data warehouse Sistem Informasi Eksekutif, Studi Kasus Data Akademik Prodi Teknik Elektro FT UGM. Yogyakarta: Universitas Gadjah Mada.

Stanciu, A., Florin, M., Radulescu, C., Aleca, O., 2009. Solutions for Decision Support in University Management. Economia. Seria Management, 12(1), pp.136-151.

Turban, E., Aronson, Jay E., Liang, T., Sharda, R., 2006. Decision Support and Business Intelligence Systems, 8th ed. Upper Saddle River, NJ: Pearson Prentice Hall. 
Jurnal Sistem Informasi, Volume 5, Nomor 3, Maret 2015, 281-291 